\title{
Propidium monoazide RTqPCR assays for the assessment of hepatitis A inactivation and for a better estimation of the health risk of contaminated waters
}

\author{
Noemí Fuster, ${ }^{\mathrm{a}, \mathrm{b}}$ Rosa M. Pintó, ${ }^{\mathrm{a}, \mathrm{b}}$ Cristina Fuentes, ${ }^{\mathrm{a}, \mathrm{b}}$ Nerea Beguiristain, ${ }^{\mathrm{a}, \mathrm{b}}$ Albert Bosch, ${ }^{\mathrm{a}, \mathrm{b}}$ Susana Guix ${ }^{\mathrm{a}, \mathrm{b}, *}$ \\ ${ }^{a}$ Enteric Virus Group, Department of Microbiology, University of Barcelona, Avda Diagonal 643, 08028 Barcelona, Spain \\ ${ }^{\mathrm{b}}$ Nutrition and Food Safety Research Institute (INSA-UB), University of Barcelona, Avda Prat de la Riba 171, 08921 Santa Coloma de Gramanet, Spain
}

\section{A R T I C L E I N F O}

Article history:

Received 30 December 2015

Received in revised form 24 May 2016

Accepted 27 May 2016

Available online $\mathrm{xxx}$

Keywords:

Hepatitis A virus

RTqPCR

Propidium monoazide

Infectivity

Disinfection

Free chlorine

Thermal inactivation

\section{A B S T R A C T}

The waterborne transmission of hepatitis A virus (HAV), the main cause of acute hepatitis, is well documented. Recently, two ISO proposals for sensitive determination of this pathogen by RTqPCR in water and food have been published (ISO/ TS 15216-1 and ISO/TS 15216-2), and could enable the formulation of regulatory standards for viruses in the near future. However, since detected viral genomes do not always correlate with virus infectivity, molecular approaches need to be optimized to better predict infectivity of contaminated samples. Two methods involving the use of propidium monoazide (PMA), with or without Triton X-100, prior to RTqPCR amplification were optimized and adapted to infer the performance of infectious viral inactivation upon two different water treatments: free chlorine and high temperature. Significant correlations between the decrease of genome copies and infectivity were found for both inactivation procedures. The best procedure to infer chlorine inactivation was the PMA-RTqPCR assay, in which 1,2 or 3-log genome copies reductions corresponded to reductions of infectious viruses of $2.61 \pm 0.55,3.76 \pm 0.53$ and $4.92 \pm 0.76 \operatorname{logs}$, respectively. For heatinactivated viruses, the best method was the PMA/Triton-RTqPCR assay, with a 1, 2 or 3-log genome reduction corresponding to reductions of infectious viruses of $2.15 \pm 1.31,2.99 \pm 0.79$ and $3.83 \pm 0.70 \mathrm{logs}$, respectively. Finally, the level of damaged virions was evaluated in distinct types of water naturally contaminated with HAV. While most HAV genomes quantified in sewage corresponded to undamaged capsids, the analysis of a river water sample indicated that more than $98 \%$ of viruses were not infectious. Although the PMA/Triton-RTqPCR assay may still overestimate infectivity, it is more reliable than the RTqPCR alone and it seems to be a rapid and cost-effective method that can be applied on different types of water, and that it undeniably provides a more accurate measure of the health risk associated to contaminated waters.

(C) 2016 Published by Elsevier Ltd.

\section{Introduction}

Water is an important source of human exposure to gastroenteric diseases, mainly as a result of the ingestion of fecally contaminated water or food irrigated with it (Bosch et al., 1991, Severi et al., 2015). One of the better characterized waterborne viral pathogen for humans is hepatitis A virus (HAV), which is the etiological agent of the most common type of hepatitis. These viruses are shed in feces as nonenveloped virus particles containing a positive-sense single-stranded RNA genome. In 2013-14, a huge HAV outbreak affecting over 1500 patients hit Europe due to the consumption of frozen berries (Severi et al., 2015). Although the contamination source has not been determined, such a broad contamination could be suspected in the irrigation water. Recently, two ISO proposals for sensitive and quantitative determination of HAV in water and several food matrices have been published and could enable the formulation of regulatory standards for viruses in the near future (ISO/TS15216-1 and 2, 2013). These methods are based on real time reverse transcription quantitative PCR (RTqPCR), which is fast and extremely sensitive, but since detected viral genomes are not always indicative of virus infectivity, molecular

\footnotetext{
* Corresponding author. Department of Microbiology, University of Barcelona, Avda Diagonal 643, 08028 Barcelona, Spain.

Email address: susanaguix@ub.edu (S. Guix)
}

approaches need to be optimized to better predict infectivity of contaminated samples. Although HAV cell-culture adapted strains are available, unfortunately wildtype viruses are extremely difficult to grow in vitro and infectivity assays in cell culture are not available for their detection in water.

Common procedures for water disinfection include chlorine and heat treatment, but the inability of molecular tests to distinguish between inactivated and infectious virions has hampered the assessment of the efficiency of disinfection methods. In the last years, several reports have recommended the use fluorescent of dyes such as ethidium monoazide (EMA) or propidium monoazide (PMA) for the livedead differentiation in molecular tests (Elizaquível et al., 2014). These dyes enter damaged viral capsids and bind to double-stranded nucleic acid after a photo-activation step, thus preventing RNA retrotranscription and further amplification by RTqPCR. However, the efficacy of the treatment depends on the target virus as well as the disinfection procedure (Karim et al., 2015; Kim et al., 2011, Leifels et al., 2015; Parshionikar et al., 2010) . Factors such as the degree of secondary structure present within the target RTqPCR region, its level of interaction and protection by capsid proteins, or the mechanical stability or plasticity of the viral capsid may explain why the efficiency of EMA/PMA-RTqPCR methods varies among viral targets and inactivation mechanisms. However, few studies have addressed the ap- 
plicability of these methods on water (Moreno et al., 2015; Parshionikar et al., 2010).

The main goal of our study was to develop a PMA/RTqPCR quantitation method to be used as a tool to infer the performance of different disinfection procedures, in correlation with the reduction of infectious titers. Several PMA concentrations were tested, and the effect of Triton X-100 was studied because it has been previously shown to enhance PMA action (Coudray-Meunier et al., 2013; Moreno et al., 2015). HAV was selected because it is highly stable in the environment and particularly resistant to disinfectants and heating (Abad et al. 1994, 1997; Fraisse et al., 2011; Sow et al., 2011). As a disinfection method, we used free chlorine, which alters the viral capsid but which have also been reported to damage specific genomic regions ( $\mathrm{Li}$ et al., 2002), and heat treatment at temperatures over $70{ }^{\circ} \mathrm{C}$, which mainly affects virus capsid (Costafreda et al., 2014). Viral inactivation experiments were performed on water containing high levels of chloride salts to simulate river waters from our geographic area in the Mediterranean coast of Spain, which frequently show high salinity, and which may be a source of contamination when used to irrigate crops. Additionally, naturally contaminated water samples were analyzed to assess the applicability of the method on real matrices.

\section{Methods}

\subsection{Cell line, virus propagation and titration}

The cell-adapted cytopathogenic pHM175 43c strain of HAV (kindly provided by T. Cromeans, Centers for Disease Control and Prevention, Atlanta, GA) was grown in FRhK-4 cells as previously described (Aragones et al., 2008). Inactivated viruses and control viruses were titrated by $\mathrm{TCID}_{50}$ in the same cell line as previously described (Costafreda et al., 2014).

\subsection{Hypochlorite inactivation treatment}

Virus stocks were suspended at $1 \times 10^{6} \mathrm{TCID}_{50} / \mathrm{ml}$ in 3-ml aliquots in water with a chloride concentration of around $8 \mathrm{~g} / \mathrm{L}$. Sodium hypochlorite was added to achieve an initial concentration of free chlorine (FC) of $0,2.5,5$ and $10 \mathrm{mg} / \mathrm{L}$, and samples were incubated for $30 \mathrm{~min}$ at room temperature (RT). FC was measured by the DPD ( $N, N$-diethyl- $p$-phenylenediamine sulfate) method using a portable photometer (HI 96734, HANNA Instruments). Each experiment included 2 replicas for each condition, and each condition was tested in at least 3 different experiments. After inactivation, $1 \%$ thiosulfate was added to neutralize FC. Viral inactivation was examined by measuring the loss of infectivity by determination of the $\mathrm{TCID}_{50}$ and by examining the loss of genome copy titers by PMA-RTqPCR.

\subsection{Heat treatment}

Viruses were suspended at $1 \times 10^{6} \mathrm{TCID}_{50} / \mathrm{ml}$ in $3-\mathrm{ml}$ aliquots in water with a chloride concentration of around $8 \mathrm{~g} / \mathrm{L}$, and incubated at $70{ }^{\circ} \mathrm{C}, 85^{\circ} \mathrm{C}$ and $99^{\circ} \mathrm{C}$ for $5 \mathrm{~min}$. Aliquots of virus suspensions were kept at RT and used as controls. Each experiment included 2 replicas for each condition. As above, viral inactivation was examined by measuring the loss of infectivity using the $\mathrm{TCID}_{50}$ assay and by the loss of genome copy titers by PMA-RTqPCR assays.

\subsection{Propidium monoazide (PMA) RTqPCR assay}

PMA solution (GenIUL, Spain) was dissolved in water and added to each sample at the concentrations ranging from 0 to $200 \mu \mathrm{M}$.
When indicated, $0.5 \%$ Triton X-100 (Panreac) was added. Samples were incubated in the dark during $5 \mathrm{~min}$ at RT with shaking to allow reagent penetration. Then, samples were exposed to light for 15 min using a continuous light in a photo-activation system (LedActive Blue, Geniul, Spain). After cross-linking, RNA was extracted using the NucleoSpin ${ }^{\circledR}$ RNA virus kit (Macherey-Nagel GmbH \& Co., Duren, Germany) according to the manufacturer's instructions. HAV genome copies were titrated by one-step RTqPCR assay using the RNA UltraSense One-Step quantitative system (Invitrogen SA) and the Strategene Mx3000P system following the standardized ISO guidelines (ISO/TS15216-1 and 2, 2013). The set of primers and probe used target the $5^{\prime}$ non coding region $\left(5^{\prime} \mathrm{NCR}\right)$ of the HAV genome and have been previously validated (Costafreda et al., 2006; Pintó et al., 2009). Forward primers, reverse primer and probe concentrations were $500 \mathrm{nM}, 900 \mathrm{nM}$ and $250 \mathrm{nM}$, respectively. Cycling parameters were $1 \mathrm{~h}$ at $55^{\circ} \mathrm{C}$ followed by $5 \mathrm{~min}$ at $95^{\circ} \mathrm{C}$, and 45 cycles of $15 \mathrm{~s}$ at $95^{\circ} \mathrm{C}, 1 \mathrm{~min}$ at $60^{\circ} \mathrm{C}$ and $1 \mathrm{~min}$ at $65^{\circ} \mathrm{C}$. Non PMA-treated samples were quantified in parallel.

\subsection{Analysis of naturally contaminated water samples}

Concentrated water samples from a previous survey conducted along the Llobregat river catchment in Spain between 2007 and 2009 (Pérez-Sautu et al., 2012) which had tested positive for HAV were analyzed: a freshwater concentrate (S3-Nov07) and an untreated sewage concentrate (S5-Apr09). In addition, a sewage sample collected from the municipal wastewater treatment plant of Marrakesh in August 2015 was concentrated and analyzed. The freshwater sample was concentrated from $10 \mathrm{~L}$ by filtration through positively charged glass wool and polyethylene glycol (PEG) precipitation, and the untreated sewage samples were concentrated by PEG precipitation using a starting volume of 0.6 L (Pérez-Sautu et al., 2012). RTqPCR assays supplemented or not with PMA and Triton X-100 were performed as described above, and a process control virus (mengovirus) and an external control were included to monitor extraction and RTqPCR efficiencies following the ISO guidelines. Quantifications were repeated at least in duplicate.

\subsection{Statistical analysis}

All inactivation experiments were performed at least in triplicate. Comparisons between means were performed using the student t-test (unpaired) using the IBM SPSS ${ }^{\circledR}$ Statistics version 20 software (SPSS Inc., Chicago, IL, USA). Correlation analyses between the level of inactivation measured by the infectivity assay and the molecular assays were performed using Microsoft Excel 2010. P values $<0.05$ were considered statistically significant.

\section{Results}

\subsection{PMA-RTqPCR assay development}

In order to establish the optimal conditions for the PMA-RTqPCR assay, HAV suspensions at a concentration of $10^{5} \mathrm{TCID} 50 / \mathrm{ml}$ were completely inactivated by incubation with $10 \mathrm{mg} / \mathrm{L}$ of free chlorine for $30 \mathrm{~min}$ at RT, and samples were incubated at $0,25,100$ or $200 \mu \mathrm{M}$ of PMA and irradiated using continuous light. Results shown in Table 1 indicate that the use of PMA at $200 \mu \mathrm{M}$ provided significantly higher differences between infectious and inactivated viruses $(p<0.05)$. 
Table 1

Quantification by RTqPCR after PMA treatment at 25,100 or $200 \mu \mathrm{M}$ in infectious and inactivated HAV suspensions inactivated by free chlorine (average \pm standard deviation, $\mathrm{n}=3$ ).

\begin{tabular}{llll}
\hline $\begin{array}{l}\text { PMA } \\
\begin{array}{l}\text { concentration } \\
(\mu \mathrm{M})\end{array}\end{array}$ & $\begin{array}{l}\text { Infectious HAV }(\log \\
\text { genome copies/ml) }\end{array}$ & $\begin{array}{l}\text { Inactivated HAV }(\log \\
\text { genome copies/ml })\end{array}$ & $\begin{array}{l}\text { Log } \\
\text { reduction }\end{array}$ \\
\hline 25 & $8.33 \pm 0.27$ & $5.66 \pm 0.34$ & $2.67 \pm 0.43$ \\
100 & $7.78 \pm 0.40$ & $4.83 \pm 0.23$ & $2.95 \pm 0.46$ \\
200 & $8.39 \pm 0.18$ & $4.79 \pm 0.38$ & $3.59 \pm 0.43^{*}$ \\
\hline
\end{tabular}

${ }^{\text {a }}$ Reduction in titers obtained between inactivated viruses before and after PMA treatment. ANOVA test $(* \mathrm{p}<0.05)$.

\subsection{Monitoring HAV inactivation by PMA-RTqPCR assays}

Average levels of inactivation after different chlorine and heat treatments were evaluated both by $\mathrm{TCID}_{50}$ assays and by several molecular assays, and compared (Fig. 1). Molecular assays included RTqPCR alone, RTqPCR after PMA treatment at the optimized conditions (PMA-RTqPCR), and RTqPCR after PMA treatment supplemented with Triton X-100 (PMA/Triton-RTqPCR). In the infectivity assays, no cytotoxicity was observed on FRhK-4 cells due to the use of FC and thiosulfate during the inactivation process (data not
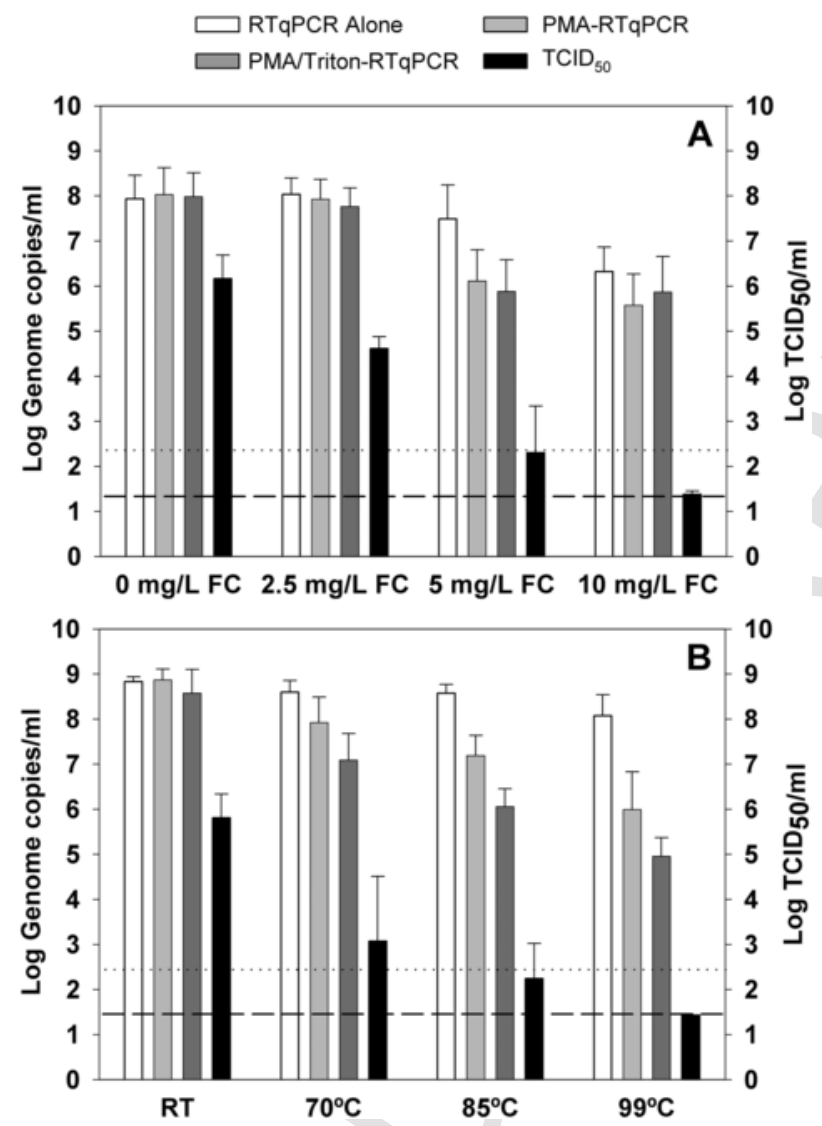

Fig. 1. Inactivation of HAV by free chlorine treatment (A) and high temperature (B), as determined by molecular (RTqPCR alone, PMA-RTqPCR and PMA/Triton-RTqPCR) and infectivity methods $\left(\mathrm{TCID}_{50}\right)$. Titers are expressed as average \pm standard deviation. Dashed lines indicate the detection limit for the $\mathrm{TCID}_{50}$ assay. Dotted lines indicate the detection limit for the molecular assays. Experiments were performed at least in triplicate. shown). Since treatment of samples with PMA did not significantly reduce infectivity (Fig. S1; $\mathrm{p}=0.108$ ), $\mathrm{TCID}_{50}$ titers shown in Fig. 1 correspond to samples which had been inactivated but which had not been treated with PMA. On RTqPCR assays, process control virus recoveries and percentages of RTqPCR inhibitions were valid in all cases according to the ISO criteria and were similar between samples (data not shown). A $2.5 \mathrm{mg} / \mathrm{L} \mathrm{FC}$ dose only affected the infectious titer with a reduction of $1.34 \pm 0.45 \log$ (Fig. 1A). No effects were observed in any of the genome copy numbers calculated by RTqPCR alone, PMA-RTqPCR or PMA/Triton-RTqPCR. With higher doses including 5 and $10 \mathrm{mg} / \mathrm{L}$ of FC, infectivity was reduced over $4.5 \mathrm{logs}$, and in most cases viral titers decreased below the detection limit. As expected, due to the specific damage of FC on the $5^{\prime}$ end of the HAV genome ( $\mathrm{Li}$ et al., 2002), genome titers obtained by RTqPCR alone were already significantly lower at 5 and $10 \mathrm{mg} / \mathrm{L}$ of FC $(\mathrm{p}<0.05)$ compared to untreated controls. Average log reductions obtained by molecular tests were higher when PMA was included, suggesting that PMA-RTqPCR may better reflect infectivity although differences were not statistically different from RTqPCR alone. Neither did addition of Triton X-100 enhance titer reduction (Fig. 1A).

After treatment at $70{ }^{\circ} \mathrm{C}$, infectivity was reduced $2.48 \pm 1.30$ logs (Fig. 1B). Treatment at $85^{\circ} \mathrm{C}$ and $99{ }^{\circ} \mathrm{C}$ resulted in losses of $3.58 \pm 0.32$ and $4.50 \pm 0.58 \operatorname{logs}$, respectively. Despite this high effect on infectivity, RTqPCR alone only measured a reduction lower than $1 \log$ in all cases. PMA-RTqPCR assay resulted in reductions of $0.86 \pm 0.36,1.79 \pm 0.36$ and $2.87 \pm 0.84 \operatorname{logs}$ at $70{ }^{\circ} \mathrm{C}, 85^{\circ} \mathrm{C}$ and $99^{\circ} \mathrm{C}$, respectively. Of note, PMA-RTqPCR assays combined with Triton X-100 performed better, resulting in log reductions of $1.46 \pm 0.10,2.81 \pm 0.38$ and $3.63 \pm 0.48$, which only differ in less than $1 \log$ with TICD $_{50} \log$ reductions at the 3 assayed temperatures. Interestingly, when looking at the strongest inactivation treatments ( $30 \mathrm{~min}$ at $10 \mathrm{mg} / \mathrm{L} \mathrm{FC}$ and $5 \mathrm{~min}$ at $99^{\circ} \mathrm{C}$ ), log reductions obtained by RTqPCR alone were markedly higher for FC $(1.90 \pm 0.87)$ compared to high temperature $(0.76 \pm 0.37)$.

As an additional approach to estimate correlation between molecular and infectivity methods, an analysis on the average ratio of genome copies versus infectious viruses was also performed (Fig. 2). As expected, these ratios were high when using RTqPCR alone in all cases. The addition of PMA resulted in a ratio reduction, although it was only significant when viruses were inactivated by temperatures of $99^{\circ} \mathrm{C}$ (Fig. 2B). As observed before, Triton X-100 improved correlation with infectivity only when viruses were inactivated by heat.

To assess with a higher precision the correlation between molecular and infectious measurements, linear regression analyses were performed using all data pairs. Linear regression analysis provides a better way to estimate correlation between the two variables over the wide range of inactivation levels than mean comparison. Since the ratio between infectious particles and genome copies may vary depending on the particular virus stock used for the experiments and could also be different in wildtype isolates, correlation analyses were performed for the log reductions achieved by the inactivation treatment. Individual data pairs were modeled using linear predictor functions and all pairs were considered valid after standardized residual analysis to identify outliers. The correlation between the infectious log reduction and the log reductions obtained by the applied molecular tests (RTqPCR alone, PMA-RTqPCR and PMA/Triton-RTqPCR) for HAV inactivated by $\mathrm{FC}$ is shown in Fig. 3A, 3C and 3E, respectively. The linear correlation was statistically significant in all cases but higher for the PMA-RTqPCR assay, with a correlation of 0.884 ( $\mathrm{p}$ value $5.99 \times 10^{-5}$ ). Again, a significant correlation was also observed between RTqPCR alone and infectivity (Fig 3A) due to the fact that FC specifically damages the 5'end of the HAV genome (Li et al., 2002), 

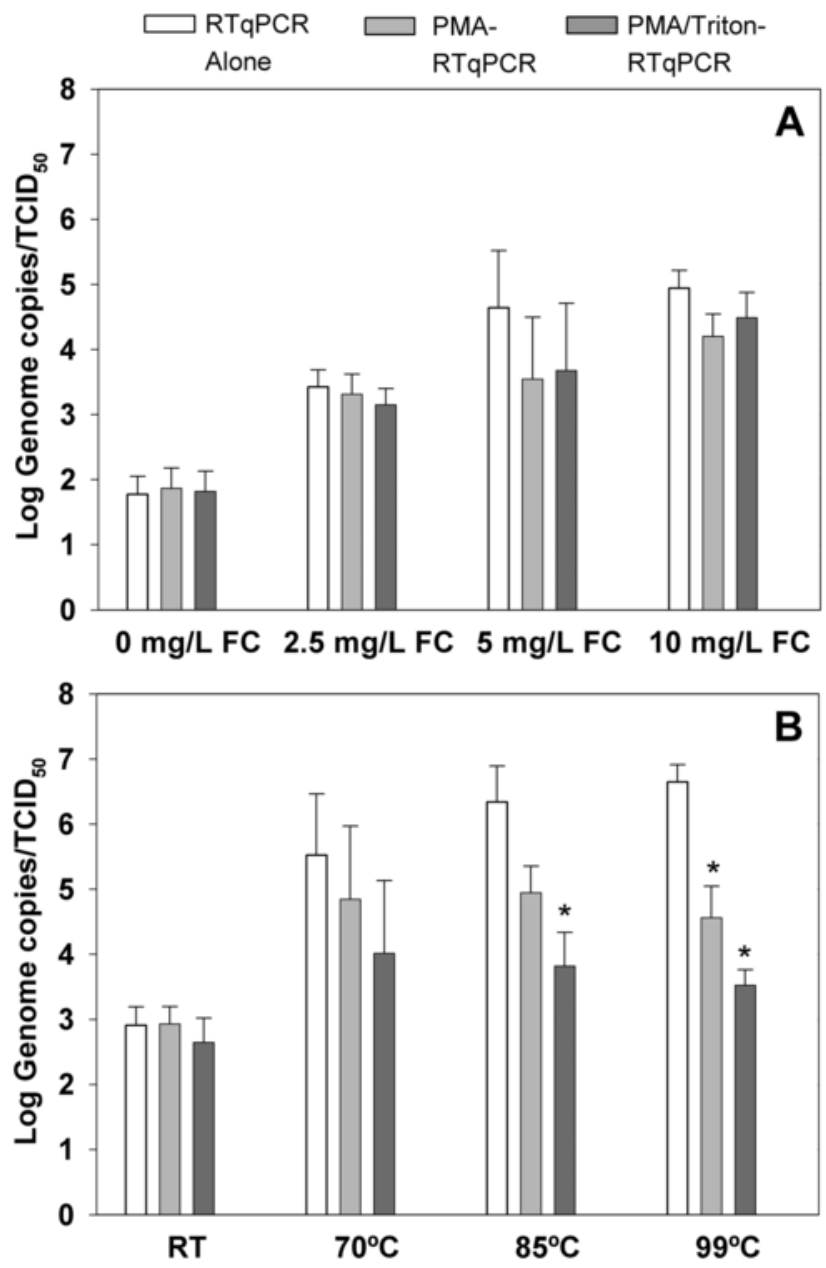

Fig. 2. Average log ratio of genome copies and $\mathrm{TCID}_{50}$ titers obtained by $\mathrm{RTqPCR}$ alone, PMA-RTqPCR and PMA/Triton-RTqPCR after inactivation by free chlorine (A) and heat treatment (B). Data are represented as mean values \pm standard error. Asterisks indicate statistically significant differences compared to the ratio obtained by RTqPCR alone $(t$-test; $\mathrm{p}<0.05)$.

but the analysis of covariance used to compare slopes from different regression lines indicated significant differences between slopes from RTqPCR alone and PMA-RTqPCR for free chlorine inactivation $(p=0.024$; Fig $3 \mathrm{~A}$ and $\mathrm{C})$. Added to the fact that the slope of PMARTqPCR is closer to 1 , these results indicate that PMA significantly improves correlation between genome copy reduction and infectious titer reduction when viruses are inactivated by FC.

Correlation analysis between infectivity and molecular log reductions for heat-inactivated HAV is shown in Fig. 3B, D and F. Correlation was only significant when PMA/Triton-RTqPCR assay was used ( $\mathrm{p}$ value of 0.024 ). Thus, while viral inactivation by chlorine treatment could be better estimated by the PMA-RTqPCR assay (Fig. 3C), inactivation by high temperature was better estimated by the PMA/TritonRTqPCR assay (Fig. 3F), confirming that addition of the surfactant was especially helpful to discriminate inactivated viruses damaged by heat. Analysis of covariance also confirmed significant differences between slopes from RTqPCR alone and PMA/Triton-RTqPCR for heat treatment $(\mathrm{p}=0.033$; Fig. 3B and $\mathrm{F})$.

In conclusion, addition of PMA improved correlation between infectivity and molecular tests both for chlorine and heat-inactivated viruses, and it was more effective in the presence of the surfactant agent only for heat-inactivated viruses. Our linear regression analyses show that molecular methods including PMA pre-treatment may be used to estimate the performance of disinfection treatments, but it should be taken into account that correlation depends on the mechanism of inactivation. For example, for chlorine-inactivated viruses, a 1,2 or $3-\log$ reduction in the PMA-RTqPCR assay would correspond to reductions of infectious viruses of $2.61 \pm 0.55,3.76 \pm 0.53$ and $4.92 \pm 0.76 \mathrm{logs}$, respectively. For heat-inactivated viruses, a 1 , 2 or 3-log reduction in the PMA/Triton-RTqPCR assay would correspond to reductions of infectious viruses of $2.15 \pm 1.31,2.99 \pm 0.79$ and $3.83 \pm 0.70 \operatorname{logs}$, respectively.

\subsection{Use of PMA-RTqPCR assays on naturally contaminated water samples}

In order to confirm the applicability of the PMA/Triton-RTqPCR assay on real water matrices, the developed method was tested using contaminated samples. We used 2 archived naturally contaminated water samples from a study conducted in 2007 (a river water sample and a sewage sample), and a fresh sewage sample collected at the time of the study. Since Triton X-100 contributed to the discrimination of viruses inactivated by high temperature and it was not detrimental in discriminating chlorine-inactivated viruses, we decided its inclusion in the assay. Samples were titrated with and without PMA/Triton treatment in parallel. The percentage of viruses with damaged capsids may be calculated comparing quantification data from the RTqPCR and the PMA/Triton-RTqPCR assay using the following formula: \% viruses with damaged capsids $=100-[$ (genome copies $/ \mathrm{L}$ PMA/Triton-RTqPCR)/(genome copies/L RTqPCR alone) $x$ 100]. Results from the analysis of 3 HAV positive samples are shown in Table 2. Each sample was quantified at least twice. While treatment with PMA/Triton reduced HAV genome copy numbers $1.75 \pm 0.48$ logs in the river water sample, the titer difference for the two analyzed sewage samples was very low. In order to confirm that PMA/Triton treatment was able to reduce the signal of inactivated viruses in sewage concentrates, parallel aliquot samples were heated for $5 \mathrm{~min}$ at $85^{\circ} \mathrm{C}$ before quantification. As expected, heat treatment resulted in a reduction of titer in all samples (Table 2). These results suggest that while more than $98 \%$ of genomes quantified in the river water concentrate were not infectious due to capsid damage, most genomes detected in sewage are likely to be infectious.

\section{Discussion}

One of the main challenges in public health is the evaluation of risks associated with water samples that are positive for viruses by a molecular assay. Availability of sensitive culture-independent molecular tests that correlate with infectious titers will be a key step in risk assessment studies, especially for non-cultivatable pathogenic viruses such as HAV. Molecular methods that measure capsid integrity, such as the use of intercalating dyes prior to RTqPCR, have been explored by different laboratories (Karim et al., 2015; Moreno et al., 2015; Parshionikar et al., 2010), and it seems that there is no universal pattern of behaviour. In this study we have examined the correlation of two different PMA-RTqPCR assays (with and without Triton X-100) with the infectious titer of HAV after inactivation by FC and high temperature. Our results confirm the observation that both treatments lead to capsid damage allowing PMA penetration and show that correlation between infectivity assays and molecular tests depends on the mechanisms of virus inactivation. Indeed, heat inactivation at temperatures higher than $40{ }^{\circ} \mathrm{C}$ mainly affects virus capsids and $\mathrm{FC}$ has been shown to target both the capsid and the genome (Costafreda et al., 2014; Li et al., 2002). For HAV, inactivation by chlorine at high doses has been reported to be due to the loss of the $5^{\prime} \mathrm{NCR}$ of the viral genome ( $\mathrm{Li}$ et al., 2002), and our results are consistent with these 


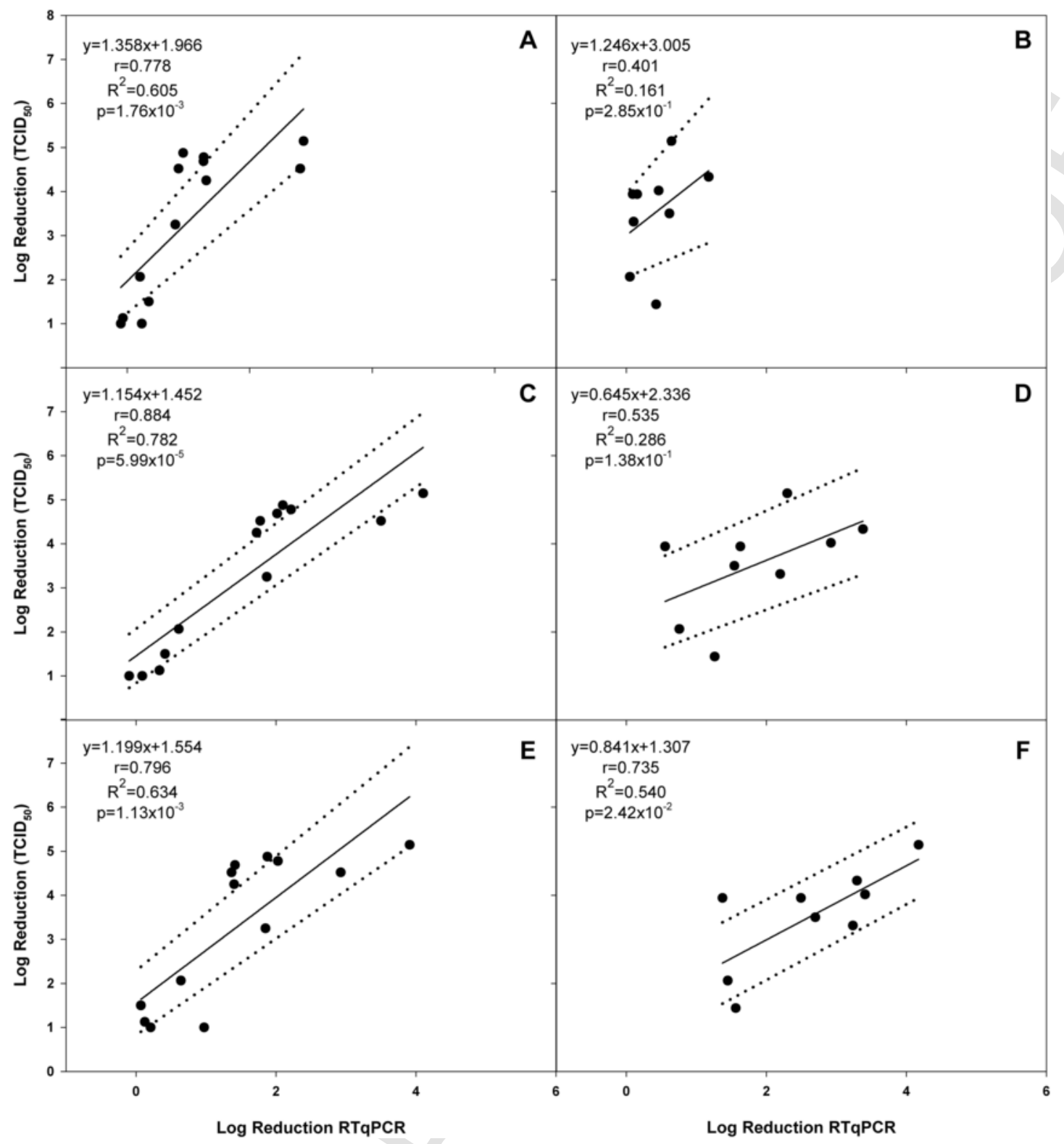

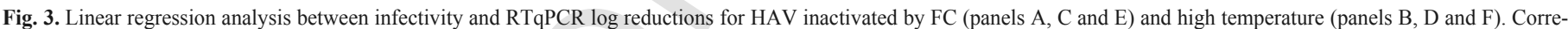

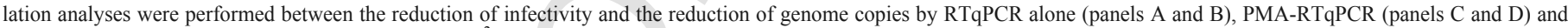
PMA/Triton-RTqPCR (panels E and F). Equations, $r, \mathrm{R}^{2}$ and $\mathrm{p}$ values are shown for each plot. Dashed lines indicate $95 \%$ confidence intervals.

observations. When HAV was inactivated by FC, correlation between $\mathrm{TCID}_{50}$ and RTqPCR was statistically significant even in the absence of PMA pretreatment, confirming that free chlorine does degrade the target region of the RTqPCR assay located at the $5^{\prime} \mathrm{NCR}$ of the genome.

In our study, for PMA-RTqPCR assays without Triton X-100, better correlations were observed for viruses inactivated by FC than by heat, and addition of Triton X-100 only improved PMA performance when viruses were thermally denaturated but not when they were oxidized by FC. Other studies using PMA assays without Triton X-100 have also described worse performance on other heat-inactivated viruses, compared to other inactivation mechanisms (Karim et al., 2015; Leifels et al., 2015; Parshionikar et al., 2010), and addition of Triton X-100 has been shown to improve discrimination of infectious HAV after heat inactivation (Coudray-Meunier et al., 2013; et al., 2015). However, the effect of Triton X-100 had not yet been assessed on other inactivation processes different from heat. The molecular bases for the differential effect of Triton X-100 observed depending on the inactivation mechanisms are unclear. Since PMA requires double-stranded or structured nucleic acids for binding, its binding to nucleic acids may be less efficient when viruses are inactivated by heat due to denaturation of stable secondary structures present within genomes. In this type of samples, Triton X-100 and other surfactants may facilitate reannealing of RNA secondary structures on genomic regions, which are essential for PMA covalent binding.

Overall, despite significant correlations found between log reductions of infectious titers and genome copy titers, it seems that PMARTqPCR assays cannot completely prevent amplification and detection of inactivated viruses. In our hands, despite the high level of viral inactivation, we did not get any RTqPCR result with a 
Table 2

Quantification of HAV present in naturally contaminated water samples by RTqPCR alone, and PMA/Triton RTqPCR assays (average \pm standard deviation, $\mathrm{n}=2-3$ ).

\begin{tabular}{|c|c|c|c|c|}
\hline Sample & Treatment & $\begin{array}{l}\text { RTqPCR alone } \\
\text { (log genome } \\
\text { copies/L) }\end{array}$ & $\begin{array}{l}\text { PMA/Triton- } \\
\text { RTqPCR (log } \\
\text { genome copies/L) }\end{array}$ & $\begin{array}{l}\text { Log } \\
\text { reduction }^{\mathrm{a}}\end{array}$ \\
\hline \multirow{2}{*}{$\begin{array}{c}\text { River water } \\
\text { S3 Nov07 }\end{array}$} & Untreated & $3.12 \pm 0.27$ & $1.37 \pm 0.21$ & $1.75 \pm 0.48$ \\
\hline & $\begin{array}{l}5 \text { min at } \\
85^{\circ} \mathrm{C}\end{array}$ & NT & NT & NT \\
\hline \multirow{2}{*}{$\begin{array}{l}\text { Wastewater } \\
\text { S5 Apr09 }\end{array}$} & Untreated & $5.46 \pm 0.99$ & $5.35 \pm 0.77$ & $0.11 \pm 0.23$ \\
\hline & $\begin{array}{l}5 \text { min at } \\
85^{\circ} \mathrm{C}\end{array}$ & $5.79 \pm 0.40$ & $4.55 \pm 0.23$ & $1.49 \pm 0.28$ \\
\hline \multirow{2}{*}{$\begin{array}{l}\text { Wastewater } \\
\text { M1 Aug15 }\end{array}$} & Untreated & $5.16 \pm 0.11$ & $5.32 \pm 0.11$ & $-0.16 \pm 0.23$ \\
\hline & $\begin{array}{c}5 \text { min at } \\
85^{\circ} \mathrm{C}\end{array}$ & $4.65 \pm 0.33$ & $\leq 3.42 \pm 0.0$ & $\geq 1.23 \pm 0.33$ \\
\hline
\end{tabular}

NT: Not tested.

${ }^{\mathrm{a}} \mathrm{Log}$ reduction in titer compared to $\mathrm{RTqPCR}$ alone.

genome copy titer below the limit of detection of the assay $(2.30 \operatorname{logs}$ genome copies $/ \mathrm{ml}$ and $1.43 \operatorname{logs} \mathrm{TCID}_{50} / \mathrm{ml}$ ) in any of the experiments performed, highlighting the fact that molecular PMA assays are likely to overestimate virus infectivity. Since treatment of purified HAV RNA with PMA completely abolishes RTqPCR signal (data not shown), it seems that this limitation is not due to the stoichiometric ratio between genome copies and dye molecule, neither of the degree of secondary structures within the target region. PMA assays with modified $\mathrm{pH}$ or after supplementation with nucleic acid hexamers to induce the formation of double-stranded regions have been performed in our laboratory and did not provide any improvement on the procedure (data not shown). Whether PMA entry into damaged particles may be hindered by viral aggregation, or by capsid lack of plasticity and flexibility remains to be elucidated. In addition, it is also possible that viral capsids suffer structural alterations that render them non-infectious without causing holes through which intercalator molecules can get inside. More than likely, the population of inactivated viruses is not homogeneous.

In summary, our study shows that although PMA-RTqPCR assays are not a perfect tool to directly predict the concentration of infectious viruses, they are useful in inferring the efficiency of several water treatments on infectious virus removal. Linear correlations may be employed as a culture-independent tool to estimate the level of disinfection reached upon a certain inactivation process. Thus, for example, for chlorine-inactivation, a 1, 2 or 3-log reduction in the PMA-RTqPCR assay corresponds to reductions of infectious viruses of $2.61 \pm 0.55,3.76 \pm 0.53$ and $4.92 \pm 0.76 \mathrm{logs}$, respectively. For heat-inactivated viruses, a 1,2 or $3-\log$ reduction in the PMA/Triton-RTqPCR assay corresponds to reductions of infectious viruses of $2.15 \pm 1.31,2.99 \pm 0.79$ and $3.83 \pm 0.70 \mathrm{logs}$, respectively.

In addition, we have confirmed the applicability of PMA assays to estimate the proportion of "non-infectious" viruses present in naturally contaminated water samples. We demonstrate that PMA/Triton-RTqPCR assays are suitable for the analysis of naturally contaminated water samples of different kinds without further sample dilution, providing a better estimation of the infectious titer. An additional advantage of applying PMA-RTqPCR tests on water samples is that PMA may prevent amplification of non-specific free nucleic acids. Due to the scarcity of water samples naturally contaminated with HAV in our area, two of the analyzed samples came from a previous study that had been archived at $-80^{\circ} \mathrm{C}$ for $5-7$ years (Pérez-Sautu et al., 2012), and although HAV capsids have been shown to be highly stable (Costafreda et al., 2014), the levels of dam- aged virions may have been modified during storage. Although our results suggest that the percentage of non-infectious HAV, and the resulting risk for humans, may be significantly different between the different types of analyzed water samples, the possibility that the long storage time has affected the capsid stability of viruses contaminating the river water sample cannot be completely ruled out.

In conclusion, although PMA-RTqPCR assays may still overestimate the amount of infectious viruses, acknowledging that a certain percentage of viral genomes present in water are not infectious due to capsid damage undeniably provides a better assessment of the associated risk. This may be highly relevant in outbreak situations in which a waterborne origin is suspected.

\section{Conclusions}

- $\quad$ The treatment of samples with PMA prior to RTqPCR amplification may be used to infer the performance of HAV disinfection treatments.

- $\quad$ Addition of Triton enhances correlation with infectivity for heatinactivated viruses, but not for free chlorine inactivated viruses.

- Despite the positive effect of Triton may not be universal, the potential use of PMA/Triton-RTqPCR assays as a horizontal method to monitor a reduction in virus infectivity is promising.

- $\quad$ PMA/Triton-RTqPCR assays may be used as a refinement for a better estimation of the concentration of infectious particles in naturally contaminated waters.

- $\quad$ Accurate quantification of intact viruses present in water will be of enormous value in performing and interpreting quantitative risk assessment studies.

\section{Conflict of interest}

No conflict of interest declared.

\section{Funding information}

This work was supported in part by projects BIO2014-53285 (Ministry of Economy and Competitiveness, Spain) and XRB-Biotechnolgy Reference Network (Generalitat de Catalunya), and FoodFP7-311846 (European Union). The funders had no role in study design, data collection and interpretation, or the decision to submit the work for publication.

\section{Acknowledgments}

We are indebted to Dr Mohamed Farissi at the Sultan Moulay Sliman University, Morocco, for supplying water samples.

\section{Appendix A. Supplementary data}

Supplementary data related to this article can be found at http://dx. doi.org/10.1016/j.watres.2016.05.086.

\section{References}

Abad, F.X., Pintó, R.M., Bosch, A., 1997. Disinfection of human enteric viruses on fomites. FEMS Microbiol. Lett. 156 (1), 107-111.

Abad, F.X., Pintó, R.M., Diez, J.M., Bosch, A., 1994. Disinfection of human enteric viruses in water by copper and silver in combination with low levels of chlorine. Appl. Environ. Microbiol. 60 (7), 2377-2383.

Aragones, L., Bosch, A., Pintó, R.M., 2008. Hepatitis A virus mutant spectra under the selective pressure of monoclonal antibodies: codon usage constraints limit capsid variability. J. Virol. 82 (4), 1688-1700. 
Bosch, A., Lucena, F., Diez, J.M., Gajardo, R., Blasi, M., Jofre, J., 1991. Waterborne viruses associated with a hepatitis outbreak. J. Am. Water Works Ass 83, 80-83.

Costafreda, M.I., Bosch, A., Pintó, R.M., 2006. Development, evaluation, and standardization of a real-time TaqMan reverse transcription-PCR assay for quantification of hepatitis A virus in clinical and shellfish samples. Appl. Environ. Microbiol. 72 (6), 3846-3855.

Costafreda, M.I., Pérez-Rodríguez, F.J., D'Andrea, L., Guix, S., Ribes, E., Bosch, A., Pintó, R.M., 2014. Hepatitis A virus adaptation to cellular shutoff is driven by dynamic adjustments of codon usage and results in the selection of populations with altered capsids. J. Virol. 88 (9), 5029-5041.

Coudray-Meunier, C., Fraisse, A., Martin-Latil, S., Guillier, L., Perelle, S., 2013. Discrimination of infectious hepatitis A virus and rotavirus by combining dyes and surfactants with RT-qPCR. BMC Microbiol. 13, 216.

Elizaquível, P., Aznar, R., Sánchez, G., 2014. Recent developments in the use of viability dyes and quantitative PCR in the food microbiology field. J. Appl. Microbiol. $116(1), 1-13$.

Fraisse, A., Temmam, S., Deboosere, N., Guillier, L., Delobel, A., Maris, P., Vialette, M., Morin, T., Perelle, S., 2011. Comparison of chlorine and peroxyacetic-based disinfectant to inactivate Feline calicivirus, Murine norovirus and Hepatitis A virus on lettuce. Int. J. Food Microbiol. 151 (1), 98-104.

ISO/TS15216-1 and 2, 2013. Norovirus and Hepatitis A Virus Analyses from Food and Animal Feed.

Karim, M.R., Fout, G.S., Johnson, C.H., White, K.M., Parshionikar, S.U., 2015. Propidium monoazide reverse transcriptase PCR and RT-qPCR for detecting infectious enterovirus and norovirus. J. Virol. Methods 219, 51-61.

Kim, K., Kitajima, K.H., Tohya, M., Ohgaki S, Y., 2011. Development of a real-time RT-PCR assay combined with ethidium monoazide treatment for RNA viruses and its application to detect viral RNA after heat exposure. Water Sci. Technol. 63 (3).

Leifels, M., Jurzik, L., Wilhelm, M., Hamza, I.A., 2015. Use of ethidium monoazide and propidium monoazide to determine viral infectivity upon inactivation by heat, UV- exposure and chlorine. Int. J. Hyg. Environ. Health 218 (8), 686-693.
Li, J.W., Xin, Z.T., Wang, X.W., Zheng, J.L., Chao, F.H., 2002. Mechanisms of inactivation of hepatitis a virus by chlorine. Appl. Environ. Microbiol. 68 (10), 4951-4955.

Moreno, L., Aznar, R., Sánchez, G., 2015. Application of viability PCR to discriminate the infectivity of hepatitis A virus in food samples. Int. J. Food Microbiol. 201, 1-6.

Parshionikar, S., Laseke, I., Fout, G.S., 2010. Use of propidium monoazide in reverse transcriptase PCR to distinguish between infectious and noninfectious enteric viruses in water samples. Appl. Environ. Microbiol. 76 (13), 4318-4326.

Pérez-Sautu, U., Sano, D., Guix, S., Kasimir, G., Pintó, R.M., Bosch, A., 2012. Human norovirus occurrence and diversity in the Llobregat river catchment. Spain. Environ. Microbiol. 14 (2), 494-502.

Pintó, R.M., Costafreda, M.I., Bosch, A., 2009. Risk assessment in shellfish-borne outbreaks of hepatitis A. Appl. Environ. Microbiol. 75 (23), 7350-7355.

Severi, E., Verhoef, L., Thornton, L., Guzman-Herrador, B.R., Faber, M., Sundqvist, L., Rimhanen-Finne, R., Roque-Afonso, A.M., Ngui, S.L., Allerberger, F., Baumann-Popczyk, A., Muller, L., Parmakova, K., Alfonsi, V., Tavoschi, L., Vennema, H., Fitzgerald, M., Myrmel, M., Gertler, M., Ederth, J., Kontio, M., Vanbockstael, C., Mandal, S., Sadkowska-Todys, M., Tosti, M.E., Schimmer, B., O'Gorman, J., Stene-Johansen, K., Wenzel, J.J., Jones, G., Balogun, K., Ciccaglione, A.R., O'Connor, L., Vold, L., Takkinen, J., Rizzo, C., 2015. Large and prolonged food-borne multistate hepatitis A outbreak in Europe associated with consumption of frozen berries, 2013 to 2014. Euro Surveill. 20 (29), 21192.

Sow, H., Desbiens, M., Morales-Rayas, R., Ngazoa, S.E., Jean, J., 2011. Heat inactivation of hepatitis A virus and a norovirus surrogate in soft-shell clams (Mya arenaria). Foodborne Pathog. Dis. 8 (3), 387-393. 